\title{
Patients' Satisfaction with Anticoagulant Treatment for Venous Thromboembolism
}

By Roxanne Dault MSc, Lucie Blais PhD, Alain Vanasse MD FCMF PhD, Paul Farand MD FRFCP MSc, Sylvie Perreault BPharm PhD, Geneviève Letemplier MD FRFCP, Marie-France Beauchesne PharmD

DOI: 10.22374/cjgim.v13i3.270

\begin{abstract}
About the Authors
Roxanne Dault, Alain Vanasse, Paul Farand, and Geneviève Letemplier are with the Faculté de médecine et des sciences de la santé, Université de Sherbrooke, Sherbrooke, Québec, Canada. Lucie Blais, Sylvie Perreault, and Marie-France Beauchesne are with the Faculté de pharmacie, Université de Montréal, Montréal, Québec, Canada. Lucie Blais is with the Centre de recherche, Hôpital du Sacré-Cour de Montréal, Montréal, Québec, Canada. Paul Farand, Geneviève Letemplier, and Marie-France Beauchesne are with the Centre hospitalier universitaire de Sherbrooke, Sherbrooke, Québec, Canada. Paul Farand and Marie-France Beauchesne are with the Centre de recherche, Centre hospitalier universitaire de Sherbrooke, Sherbrooke, Québec, Canada.

Corresponding Author: marie-france.beauchesne@umontreal.ca

Submitted: January 20, 2018. Accepted: March 26, 2018. Published August 27, 2018.
\end{abstract}

\begin{abstract}
\section{Background}

Data on treatment expectation and perception towards vitamin K antagonists (VKAs), direct oral anticoagulants (DOACs), and low molecular weight heparins (LMWH) for the management of venous thromboembolism (VTE) are sparse.
\end{abstract}

\section{Methods}

Prospective observational study including subjects admitted to the hospital with a diagnosis of VTE and a prescription of VKA, DOAC, or a LMWH. Treatment expectations, convenience and satisfaction were assessed using the Perception of anticoagulant treatment questionnaire (PACT-Q) at baseline and at three months.

\section{Results}

A total of 140 patients were included. Treatment expectations regarding ease of use and the ability to self-manage anticoagulation therapy were higher in patients on DOACs. However, overall treatment satisfaction scores were similar at three months between the groups.

\section{Conclusion}

Patients with VTE who are prescribed an anticoagulant have different expectations at baseline but appear to have similar treatment satisfaction regardless of the type of anticoagulant prescribed.

\section{RESUME}

\section{Antécédents}

Les données sur les attentes thérapeutiques et la perception des antagonistes de la vitamine $\mathrm{K}$ (AVK), des anticoagulants oraux directs (AOD) et des héparines de faible poids moléculaire (HFPM) pour la prise en charge de la thrombo-embolie veineuse (TEV) sont rares. 


\section{Méthodes}

Étude observationnelle prospective incluant les sujets admis à l'hôpital avec un diagnostic de TEV et une prescription d'AVK, OAD ou HFPM. Les attentes thérapeutiques, la commodité et la satisfaction ont été évaluées à l'aide du questionnaire Perception du traitement anticoagulant (PACT-Q) au début et à trois mois.

\section{Résultats}

Un total de 140 patients a été inclus. Les attentes en matière de traitement concernant la facilité d'utilisation et la capacité à gérer soi-même le traitement anticoagulant étaient plus élevées chez les patients sous AOD. Cependant, les scores globaux de satisfaction au traitement étaient similaires à trois mois entre les groupes.

\section{Conclusion}

Les patients atteints de TEV auxquels il est prescrit un anticoagulant ont des attentes différentes au départ, mais semblent avoir une satisfaction thérapeutique similaire, quel que soit le type d'anticoagulant prescrit.

Venous thromboembolism (VTE), which includes deep vein thrombosis (DVT) and pulmonary embolism (PE) is the third leading cause of vascular disease. ${ }^{1}$ Anticoagulants are the mainstay of therapy, including vitamin $\mathrm{K}$ antagonists (VKAs), direct oral anticoagulants (DOACs) and low-molecular weight heparins (LMWHs). ${ }^{2}$

When compared to VKAs, DOACs have the advantages of fixed dosing without the necessity for regular monitoring of the International Normalized Ratio (INR) and few drug/food interactions. LMWHs are preferred for the treatment of cancer associated VTE but have the inconvenience of subcutaneous administration. ${ }^{3}$

Few data are available on patients' satisfaction towards anticoagulant treatment for VTE management. Authors have reported greater satisfaction with DOACs than warfarin, ${ }^{4,5}$ but the satisfaction towards all options in the real-world setting has not been extensively assessed. The main objective of this exploratory study was to evaluate expectations, convenience and satisfaction with anticoagulant treatment in VTE patients who were admitted to a single tertiary care centre.

\section{Methods}

This was a prospective observational exploratory study. Patients at least 18 years of age, who were admitted to the emergency room or hospitalized between February 2013 and December 2014 with a diagnosis of DVT or PE (not necessarily as the primary diagnosis of admission), who could speak and read the English or French languages, and who were prescribed a VKA, a DOAC or a LMWH that was continued at discharge were eligible for inclusion. Subjects who had used an anticoagulant at a therapeutic dose in the six months prior to admission, or those unable to consent were excluded. This study was approved by the ethics committee of the Centre Hospitalier Universitaire de Sherbrooke (CHUS) and participants signed a written consent form.

Baseline characteristics (age, gender, length of stay, creatinine clearance using the CKD-EPI formula, DVT/PE diagnosis, Charlson comorbidity index) were collected. To determine patients' satisfaction, the "Perception of anticoagulant treatment questionnaire (PACT-Q)" was used. This self-administered, validated questionnaire, measures patients' satisfaction with anticoagulant treatment and treatment convenience in patients with DVT, PE, or atrial fibrillation (Cronbach's alpha of 0.84 for the "Convenience" dimension, and 0.76 for the "Anticoagulant Treatment Satisfaction" dimension) ${ }^{6,7}$ Seven questions are included in the PACT-Q1 regarding patients' expectations (on a five-point Likert-like scale, ranging from "not at all" to "extremely"/"completely"/or "very much"). Twenty questions are included in the PACT-Q2 (scored on a five-point Likert-like scale, ranging from "not at all"/"it is much worse than I expected"/"extremely dissatisfied" to "extremely"/"completely"/"very much"/it is much better than what I expected/"extremely satisfied"); 11 on treatment convenience, two on burden of disease and treatment, and seven on anticoagulant treatment satisfaction. The PACT-Q1 has to be administered before treatment initiation, but because the prescription of an anticoagulant was an inclusion criterion, it was completed as early as possible following treatment initiation during the emergency department visit or the hospitalization. The PACT-Q2 is to be administered once treatment is ongoing, and was mailed to the patient three months following discharge. The questionnaire can be completed in approximately 10 minutes and is available in the French and English languages. 
Descriptive statistics such as means and proportions were used to report baseline characteristics. Mean scores for each of the seven items of the PACT-Q1 were compared between the VKA, DOAC and LMWH groups. For the PACT-Q2, the convenience and satisfaction scores were calculated. Convenience ( $\mathrm{n}=11$ items) and burden of disease items $(n=2)$ were reversed (reversed score $=6$ - item score), added together and rescaled on a $0-100$ scale to obtain a convenience dimension score. Satisfaction items $(n=7)$ were summed and rescaled on a $0-100$ scale to determine the satisfaction dimension score. Mean scores on the PACT-Q questionnaires were compared between the groups by completing an analysis of variance (ANOVA).

\section{Results}

A total of 140 subjects were included, 63 on VKAs, 31 on DOACs (rivaroxaban was the only agent prescribed at the time of the

Table 1 Baseline Characteristics

\begin{tabular}{|c|c|c|c|c|}
\hline \multicolumn{2}{|l|}{ CHARACTERISTICS } & \multirow{2}{*}{$\begin{array}{c}\begin{array}{c}\text { VKA } \\
(n=63)\end{array} \\
60.8 \pm 18.1\end{array}$} & \multirow{2}{*}{$\begin{array}{c}\text { DOAC } \\
(n=31)\end{array}$} & \multirow{2}{*}{$\begin{array}{c}\begin{array}{c}\text { LMWH } \\
(n=46)\end{array} \\
60.2 \pm 15.9\end{array}$} \\
\hline Age (years), mean $\pm S D$ & & & & \\
\hline Male gender, n (\%) & & $29(46.0)$ & $15(48.4)$ & $26(56.5)$ \\
\hline \multirow[t]{4}{*}{ BMI $(\mathrm{kg} / \mathrm{m} 2) 1, \mathrm{n}(\%)$} & $<18.5$ & $1(1.6)$ & 0 & $2(4.3)$ \\
\hline & $18.5-24.9$ & $19(30.2)$ & $10(32.3)$ & $13(28.3)$ \\
\hline & $25.0-29.9$ & $19(30.2)$ & $10(32.3)$ & $14(30.4)$ \\
\hline & $\geq 30.0$ & $24(38.1)$ & $7(22.6)$ & $13(28.3)$ \\
\hline Current smokers, n (\%) & & $13(21.0)$ & $6(19.4)$ & $7(15.2)$ \\
\hline Length of stay (days), median; range & & $6 ; 1-108$ & $5 ; 1-91$ & $10 ; 1-49$ \\
\hline \multirow[t]{6}{*}{ Healthcare unit of admission, $\mathrm{n}(\%)$} & Internal medicine & $31(49.2)$ & $20(64.5)$ & $15(32.6)$ \\
\hline & ED & $7(11.1)$ & $1(3.2)$ & $3(6.5)$ \\
\hline & Surgery & $7(11.1)$ & $2(6.5)$ & $2(4.3)$ \\
\hline & Pulmonary & $4(6.3)$ & 0 & $9(19.6)$ \\
\hline & Cardiology & $4(6.3)$ & $2(6.5)$ & 0 \\
\hline & Others & $10(15.9)$ & $6(19.4)$ & $17(37.0)$ \\
\hline eGFR (mL/min/1.73m2), median; range & & $88.5 ; 13.6->120.0$ & $101.6 ; 43.3->120.0$ & $94.7 ; 34.9->120.0$ \\
\hline $\mathrm{GFR}<30 \mathrm{~mL} / \mathrm{min} / 1.73 \mathrm{~m} 2$ & & $4(6.3)$ & 0 & 0 \\
\hline DVT, n (\%) & & $18(29.0)$ & $10(32.3)$ & $15(32.6)$ \\
\hline$P E, n(\%)$ & & $36(58.1)$ & $17(54.8)$ & $27(58.7)$ \\
\hline DVT and PE, n (\%) & & $9(14.5)$ & $4(12.9)$ & $4(8.7)$ \\
\hline Charlson Score, mean \pm SD & & $3.1 \pm 2.3$ & $1.9 \pm 2.6$ & $5.8 \pm 3.6$ \\
\hline Number of drugs at discharge, median; range & & $8 ; 1-22$ & $7 ; 1-15$ & $9 ; 2-26$ \\
\hline
\end{tabular}

Data missing in 4 patients on DOACs and 4 on LMWH.

$\mathrm{BMI}=$ body mass index; DOACs = direct oral anticoagulants; DVT = deep vein thrombosis; $\mathrm{ED}=$ emergency department; eGFR = estimated glomerular filtration rate; $\mathrm{n}=$ number, $\mathrm{PE}=$ pulmonary embolism; SD = standard deviation. 
Table 2. Results from the PACT-Q Questionnaires

PACT-Q1: EXPECTATIONS1, Part 1

\begin{tabular}{|c|c|c|c|}
\hline $\begin{array}{l}\text { Average Score VKA } \\
(n=63), \\
\text { mean } \pm \text { SD }\end{array}$ & $\begin{array}{l}\text { Average Score } \\
\text { DOAC }(n=31) \\
\text { mean } \pm S D\end{array}$ & $\begin{array}{l}\text { Average Score } \\
\text { LMWH }(n=46) \\
\text { mean } \pm \text { SD }\end{array}$ & $p$-value \\
\hline
\end{tabular}

A1: Are you confident that your anticoagulation therapy will prevent the formation of blood clots?

\begin{tabular}{|l|l|l|l}
\hline $3.89 \pm 0.88$ & $4.26 \pm 0.68$ & $4.04 \pm 0.73$ & 0.106
\end{tabular}

A2: Do you expect that your anticoagulation therapy will relieve some of your symptoms (such as pain or swelling in your legs, palpitations, breathlessness or chest pain, etc.)?

\begin{tabular}{|l|l|l|l|}
\hline $3.54 \pm 1.22$ & $3.60 \pm 1.30$ & $3.50 \pm 1.26$ & 0.944 \\
\hline
\end{tabular}

A4: Is it important for you that your anticoagulation therapy be easy to take?

\begin{tabular}{|l|l|l|l|}
\hline $3.95 \pm 0.83$ & $4.45 \pm 0.57$ & $4.11 \pm 0.88$ & 0.019 \\
\hline
\end{tabular}

A6: Is it important for you to be able to manage your anticoagulation therapy yourself?

\begin{tabular}{|l|l|l|l|}
\hline $3.60 \pm 1.09$ & $4.00 \pm 1.18$ & $3.26 \pm 1.41$ & 0.035 \\
\hline
\end{tabular}

High score $=$ High expectations

\section{PACT-Q1: EXPECTATIONS1, Part 2}

\begin{tabular}{|c|c|c|c|}
\hline $\begin{array}{l}\text { Average Score VKA } \\
(n=63), \\
\text { mean } \pm \text { SD }\end{array}$ & $\begin{array}{l}\text { Average Score } \\
\text { DOAC }(n=31) \\
\text { mean } \pm S D\end{array}$ & $\begin{array}{l}\text { Average Score } \\
\text { LMWH }(n=46) \\
\text { mean } \pm \text { SD }\end{array}$ & $p$-value \\
\hline
\end{tabular}

A3: Do you expect your anticoagulation therapy to have side effects such as minor bruising or bleeding (for example, when shaving, cooking, minor cuts, etc.)?

$2.86 \pm 1.09$

$$
2.58 \pm 1.09
$$$$
2.59 \pm 1.13
$$$$
0.349
$$

A5: Are you worried about making mistakes when taking your anticoagulation therapy (for example, how you take it, when you take it or the dose you are taking)?

\begin{tabular}{|l|l|l|l|}
\hline $1.51 \pm 0.91$ & $1.58 \pm 0.99$ & $1.59 \pm 0.96$ & 0.893 \\
\hline
\end{tabular}

A7: Are you worried about the money you may have to spend for your anticoagulation therapy?

\begin{tabular}{|l|l|l|l|}
\hline $2.02 \pm 1.30$ & $2.42 \pm 1.29$ & $2.54 \pm 1.33$ & 0.095 \\
\hline
\end{tabular}

Low score $=$ High expectations
PACT-Q 2: Convenience and satisfaction at three months*

\begin{tabular}{|l|c|c|c|c|}
\hline $\begin{array}{l}\text { Pact-Q2 } \\
\text { dimensions } \\
\text { scores }\end{array}$ & $\begin{array}{c}\text { Average } \\
\text { Score VKA } \\
(n=37 ; 58.7 \% *), \\
\text { mean } \pm \text { SD }\end{array}$ & $\begin{array}{c}\text { Average } \\
\text { Score DOAC } \\
(n=21 ; 67.7 \% *) \\
\text { mean } \pm \text { SD }\end{array}$ & $\begin{array}{c}\text { Average } \\
\text { Score LMWH } \\
(n=23 ; 50 \% *)^{*} \\
\text { mean } \pm \text { SD }\end{array}$ & p-value \\
\hline $\begin{array}{l}\text { Convenience } \\
\text { score }\end{array}$ & $85.47 \pm 12.58$ & $87.00 \pm 9.82$ & $\begin{array}{c}86.79 \pm \\
11.97\end{array}$ & 0.864 \\
\hline $\begin{array}{l}\text { Satisfaction } \\
\text { score }\end{array}$ & $67.96 \pm 16.37$ & $\begin{array}{c}70.58 \pm \\
15.97\end{array}$ & $\begin{array}{c}70.34 \pm \\
14.98\end{array}$ & 0.782 \\
\hline
\end{tabular}

*Percentage of originally recruited subjects who returned the questionnaires.

study), and 46 on LMWHs. Mean age was younger, median length of stay was shorter, and median estimated glomerular filtration rate was higher in the DOAC group (Table 1). Overall, more subjects had a diagnosis of PE. The mean Charlson comorbidity score was higher in the LMWH group.

Results on the PACT-Q questionnaires are presented in Table 2. At baseline, subjects on a DOAC expressed higher expectations on the ease of use and self-management. At 3 months, 57 (90.5\%) subjects were still on a VKA, $26(83.9 \%)$ on a DOAC and 32 (69.6\%) on a LMWH. No statistically significant differences in treatment convenience and anticoagulation treatment satisfaction were found between the three groups.

\section{Discussion}

This study suggests that inpatients with a DVT and/or PE who are newly prescribed an anticoagulant have different treatment expectations at baseline, but similar overall treatment satisfaction, but this should be interpreted cautiously because of the low number of included subjects.

Baseline characteristics were different between the groups at baseline, which could have influenced the results. In fact, patients were younger in the DOAC group and those on LMWH had more comorbidities, which is not surprising. DOACs were more often prescribed to subjects admitted to the internal medicine unit, which could be explained by the type of patients admitted or because internists might be more comfortable with the prescription of DOACs, but this was not further investigated. Subjects who had an eGFR lower than $30 \mathrm{~mL} / \mathrm{min} / \mathrm{m}^{2}$ were prescribed warfarin, which is in accordance to prescribing guidelines. ${ }^{3}$ 
Regarding treatment expectations, patients on DOACs had higher expectations regarding ease of use and self-management. These expectations might have influenced the choice of treatment, considering that DOACs are easy to take and do not require regular monitoring of the INR. At three months, no significant differences were found in treatment convenience and satisfaction score. Greater satisfaction was found in previous studies with DOACs when compared to warfarin, but they did not include hospitalized subjects or those on LMWH. ${ }^{4,5}$ Differences in baseline characteristics, lack of power, and measurement of satisfaction using a different questionnaire could explain why we found different results. Surprisingly, subjects on LMWH did not significantly have a lower score on treatment convenience. In the context of DVT prophylaxis, Wong et al. found that $27.5 \%$ of subjects reported a preference for a subcutaneous formulation with the belief in $40.3 \%$ of them that this route was associated with a faster onset of action. ${ }^{8}$ Also, in a systematic review of studies reporting patient preferences with regard to antithrombotic treatment, it was reported that injection treatments were well tolerated, and that most patients on warfarin were generally satisfied with their treatment, but with the inconvenience of frequent blood monitoring. ${ }^{9}$ This review was completed before the availability of DOACs for VTE management.

Our study is limited by a small sample size, which could have limited the detection of significant differences, conducted in a single centre, which limits generalisability, with $59 \%$ of patients who did not answer the PACT-Q2. The PACT-Q questionnaire was used to determine patients' expectations and satisfaction, but the responsiveness, test-retest reliability properties of the questionnaire along with the value for the minimal important differences are unknown, which limits the use of this tool. Furthermore, the questionnaire was administered once treatment was instituted rather than before as recommended. Results were compared using ANOVA testing which assumes normal distribution, therefore if the measurements were not normally distributed, we may have increased the chance of false positive results. Differences in baseline characteristics were seen and we did not adjust our analysis for potential confounders, which is a limitation of this exploratory study. Finally, patients in the DOAC group were only using rivaroxaban.

This appears to be one of the first study investigating treatment satisfaction in VTE patients comparing three different treatment option and overall satisfaction was similar between the various groups, but larger observational and qualitative studies should further explore patient's satisfaction in the real-life setting.

\section{Funding}

Sanofi Canada and Pfizer Canada provided an unrestricted grant for this study. The study sponsors were not involved in the design and conduct of the study; the collection, management, analysis or interpretation of the data; or the writing or the review of the manuscript; or the decision to submit the manuscript for publication.

\section{Acknowledgements}

The authors acknowledge the Brigitte-Perrault Fund from the CHUS Foundation, Claudie Rogrigue, Katy Lavoie and Gabrielle Lefebvre for their contribution to data collection and analysis.

\section{Disclosure of Conflict of Interests}

Authors state that they have no conflicts of interest outside the grant received for the conduct of this study.

\section{References}

1. Tagalakis V, Patenaude V, Kahn SR, Suissa S. Incidence of and mortality from venous thromboembolism in a real-world population: The Q-VTE study cohort. Am J Med 2013;126:832.e13-832.e21.

2. Holbrook A, Schulman S, Witt DM, et al. Evidence-Based Management of Anticoagulant Therapy: Antithrombotic Therapy and Prevention of Thrombosis, 9th ed: American College of Chest Physicians Evidence-Based Clinical Practice Guidelines. CHEST 2012;141:e152S-84S.

3. Kearon C, Akl EA, Ornelas J et al. Antithrombotic therapy for VTE disease CHEST guideline and expert panel report. CHEST 2016;149:315-52.

4. Bamber L, Wang MY, Prins MH, et al. Patient-reported treatment satisfaction with oral rivaroxaban versus standard therapy in the treatment of acute symptomatic deep-vein thrombosis. Thromb Haemost 2013;110:732-41.

5. Prins MH, Bamber L, Cano SJ, et al. Patient-reported treatment satisfaction with oral rivaroxaban versus standard therapy in the treatment of pulmonary embolism; results from the EINSTEIN PE trial. Thrombosis Research 2015;135:281-88.

6. Prins MH, Marrel A, Carita P, Anderson D, Bousser MG, Crijns H, et al. Multinational development of a questionnaire assessing patient satisfaction with anticoagulant treatment: the 'Perception of Anticoagulant Treatment Questionnaire' (PACT-Q). Health Qual Life Outcomes 2009;7:9.

7. Prins MH, Guillemin I, Gilet H, Gabriel S, Essers B, Raskob G, et al. Scoring and psychometric validation of the Perception of Anticoagulant Treatment Questionnaire (PACT-Q). Health Qual Life Outcomes 2009;7:30.

8. Wong A, Kraus PS, Lau BD. Patient preferences regarding pharmacologic venous thromboembolism prophylaxis. J Hospit Med 2015;10:108-11.

9. MacLean S, Mulla S, Akl EA, et al. Patient values and preferences in decision making for antithrombotic therapy: a systematic review. CHEST 2012;141(2) (Suppl):e1S-e23S. 